\title{
Penaeidins, antimicrobial peptides with chitin-binding activity, are produced and stored in shrimp granulocytes and released after microbial challenge
}

\author{
Delphine Destoumieux' ${ }^{1}$, Marcello Muñoz ${ }^{1}$, Céline Cosseau1 ${ }^{1}$, Jenny Rodriguez², Philippe Bulet ${ }^{3}$, \\ Michel Comps ${ }^{4}$ and Evelyne Bachère ${ }^{1, *}$ \\ ${ }^{1}$ IFREMER/JCSCNRS/Université Montpellier 2, UMR 219 ‘Défense et Résistance chez les Invertébrés Marins', CC 80, Place \\ Eugène Bataillon, 34095 Montpellier, France \\ ${ }^{2}$ Centro Nacional de Acuicultura e Investigaciones Marinas-Escuela Superior Politecnica del Litoral, Guayaquil, Ecuador \\ 3 Institut de Biologie Moléculaire et Cellulaire, UPR 9022, CNRS, 'Réponse Immunitaire et Développement chez les Insectes', 15, \\ rue René Descartes, 67084 Strasbourg Cedex, France \\ ${ }^{4}$ IFREMER, Chemin de Maguelone, 34230 Palavas les Flots, France \\ *Author for correspondence (e-mail: ebachere@ifremer.fr)
}

Accepted 23 November 1999; published on WWW 19 January 2000

\section{SUMMARY}

Penaeidins are members of a new family of antimicrobial peptides isolated from a crustacean, which present both Gram-positive antibacterial and antifungal activities. We have studied the localization of synthesis and storage of penaeidins in the shrimp Penaeus vannamei. The distribution of penaeidin transcripts and peptides in various tissues reveals that penaeidins are constitutively synthesized and stored in the shrimp haemocytes. It was shown by immunocytochemistry, at both optical and ultrastructural levels, that the peptides are localized in granulocyte cytoplasmic granules. The expression and localization of penaeidins were further analysed in shrimp subjected to microbial challenge. We found that (1) penaeidin mRNA levels decrease in circulating haemocytes in the first 3 hours following stimulation and (2) an increase in plasma penaeidin concentration occurs after microbial challenge, together with (3) a penaeidin immunoreactivity in cuticular tissue, which can be related to the chitinbinding activity we demonstrate here for penaeidins.

Key words: Antimicrobial peptide, Chitin-binding, Haemocyte, Penaeid shrimp, Crustacean immunity

\section{INTRODUCTION}

Invertebrate immunity is based on cell defense reactions including phagocytosis, nodule formation and encapsulation. These reactions are closely associated with humoral reactions such as haemolymph coagulation, melanization or antimicrobial actions. Taken together, these various systems contribute towards the elimination of invading microorganisms (Söderhäll et al., 1996).

There have recently been important advances in our knowledge of the molecular basis of innate immunity. In particular, many studies investigated the characterization of antimicrobial peptides, which kill or inhibit the growth of micro-organisms. They are found in the plant and animal kingdoms, and as demonstrated by genetic studies on Drosophila melanogaster (Lemaitre et al., 1996), they are likely to play an essential role in organisms that lack adaptive immunity.

In arthropods, antimicrobial peptides were mainly studied in chelicerates (horseshoe crabs) and insects. Their involvement in the defense reaction is quite different in these two groups. In horseshoe crabs, they are mainly synthesized in haemocytes (invertebrate blood cells) where they are stored after processing within their cytoplasmic granules (for a review, see Iwanaga and Kawabata, 1998). They are believed to be released into haemolymph through regulated exocytosis upon microbial stimulation. This system differs from that described in insects, where the fat body is the main site for the antimicrobial peptide synthesis (Engström, 1998; Hoffmann and Reichhart, 1997), and upon injury antimicrobial peptide gene transcription is induced, resulting in their immediate synthesis and subsequent secretion into the blood. Secondary expression sites such as gonads (Manetti et al., 1998) or intestine (Ferrandon et al., 1997) were also found in insects, where different pathways regulate gene expression.

Recently, the presence of antimicrobial peptides has been reported in crustacean species including the crabs Carcinus maenas (Schnapp et al., 1996) and Callinectes sapidus (Khoo et al., 1999), and the shrimp Penaeus vannamei (Destoumieux et al., 1997), but, to date, no data were available on their localization and on their gene expression. In a previous study, we isolated and fully characterized a new family of antimicrobial peptides from the shrimp $P$. vannamei, which were named penaeidins (Destoumieux et al., 1997). Three peptides, penaeidin(Pen)-1, -2 and -3 , were isolated from haemocytes and were also found in the haemolymph, and penaeidin-3 was the most abundant penaeidin in the extracts. The three peptides show considerable similarities in their 
amino acid composition and they display a similar wide range of antifungal and antibacterial properties (Destoumieux et al., 1999). To date, we still do not know whether the three different penaeidins reflect a genetic variability at the shrimp population level or if they are all expressed in a single animal. In this paper, we investigate how, in the crustacean $P$. vanname $i$, antimicrobial peptides participate in anti-infectious responses, and consider penaeidin-3 as being representative of the penaeidin family. We give information on the site of penaeidin production and on their gene expression after microbial challenge. We demonstrate that penaeidins are mainly synthesized in haemocytes, where they are continuously produced, and then stored within cytoplasmic granules. From expression studies, we show that penaeidins are regulated upon infection following mechanisms similar to those described in horseshoe crabs and rather different from those known in insects.

\section{MATERIALS AND METHODS}

\section{Animals, tissues and haemolymph collection, and immune challenge}

Juvenile white leg shrimp (about 10-15 g), Penaeus vannamei (Crustacea, Decapoda) were obtained from the province of Guayas, Ecuador, and maintained in the laboratory in 5001 tanks (at $28^{\circ} \mathrm{C}$ ) equipped with air-lift circulating sea water. Haemolymph of animals at the intermoult stage was taken from the ventral sinus located at the base of the first abdominal segment, under an equal volume of anticoagulant Modified Alsever Solution (MAS) (27 mM sodium citrate, $336 \mathrm{mM} \mathrm{NaCl}, 115 \mathrm{mM}$ glucose, 9 mM EDTA, $\mathrm{pH}$ 7; Rodriguez et al., 1995), and immediately centrifuged at $800 \mathrm{~g}$ for 15 minutes $\left(4^{\circ} \mathrm{C}\right)$ to separate the blood cells from plasma. After haemolymph collection, shrimp tissues were harvested by dissection. Haemocytes and tissues were further treated according to different experimental procedures (see below).

Experimental immune-challenge of animals was realized as follows. A suspension $\left(50 \mu \mathrm{l} ; 10^{8}\right.$ cells/animal $)$ of heat-killed $\left(100^{\circ} \mathrm{C}, 10^{5} \mathrm{~Pa}\right.$, 20 minutes) micro-organisms including the bacterial strains Aerococcus viridans and Vibrio alginolyticus and the fungal strain Fusarium oxysporum was injected into the shrimp abdominal muscle. Haemolymph and tissue samples were collected at different times (from 0 to 72 hours) post-injection. Unchallenged animals were used as controls.

\section{DNA probe synthesis}

A penaeidin-specific probe was amplified by polymerase chain reaction (PCR) on a pen-3a cDNA clone using P3-UP (5'GTGTACAAGGGCGGTTACAC-3') as the upstream primer, and P3DW (5'-CAACAGGTTGTCAAGCGAGGT-3') as the downstream primer, as previously described (Destoumieux et al., 1997). Similarly, a genomic DNA clone corresponding to Penaeus sp. 18S rRNA (gift from Dr Trisha Spears, Florida State University, USA) was used as a template for PCR with PS18S-UP (5'-CAACTAAGAACGGCCATGC-3') and PS18S-DW (5'-GCCTTATCAGCTCTCGATTG-3'), as upstream and downstream primers, respectively. 40 cycles were used, consisting of 1 minute at $94^{\circ} \mathrm{C}, 1$ minute at $52^{\circ} \mathrm{C}$ and 1 minute at $72^{\circ} \mathrm{C}$. After electrophoresis, the amplified DNA fragments were eluted from frozen-thawed agarose by centrifugation (15 minutes, $13000 \mathrm{~g}$ ) onto a Microspin column (nylon $0.45 \mu \mathrm{m}$, PolyLabo), ethanol-precipitated, reconstituted in MilliQ water (Millipore ${ }^{\mathrm{TM}}$ ) and kept at $-20^{\circ} \mathrm{C}$ until use.

\section{Northern blot analysis}

Total RNA was extracted from P. vannamei tissues and haemocytes using Trizol reagent (BRL, Life technologies). 2 or $10 \mu \mathrm{g}$ of each sample, extracted from haemocytes or tissues, respectively, were loaded for RNA electrophoresis on a $1 \%$ agarose gel containing $17 \%$ formaldehyde and transferred to Hybond-N filter membranes (Amersham) by vacuum blotting. cDNA probes were prepared by radiolabelling the PCR-amplified fragments by random priming using the Ready-to-Go DNA labelling kit (Pharmacia). The membranes were hybridized at $55^{\circ} \mathrm{C}$ for 12 hours with the ${ }^{32} \mathrm{P}$-labeled pen-3a cDNA fragment in a solution containing $50 \%$ formamide, $5 \times \mathrm{SSC}, 8 \times$ Denhardt's solution, $0.05 \mathrm{M}$ sodium phosphate, $\mathrm{pH}$ 6.5, 0.1\% SDS and $100 \mu \mathrm{g} / \mathrm{ml}$ denatured salmon sperm. The filters were washed in $0.2 \times \mathrm{SSC}, 0.1 \% \mathrm{SDS}$ at $65^{\circ} \mathrm{C}$ followed by autoradiography. After stripping (boiling solution of $0.1 \%$ SDS onto the blot), the membranes were hybridized under identical conditions with the ${ }^{32} \mathrm{P}$-labeled ribosomal DNA probe and further subjected to autoradiography or signal quantification using the STORM ${ }^{\mathrm{TM}}$ system.

\section{Peptide extraction and high pressure liquid chromatography (HPLC) analysis}

At different times ranging from 0 to 72 hours after microbial challenge, haemolymph was collected from 10 shrimps. Cells were removed by centrifugation $\left(800 \mathrm{~g}, 15\right.$ minutes, $4^{\circ} \mathrm{C}$ ) and plasma samples (cell-free haemolymph) were pooled. After addition of aprotinin $(40 \mu \mathrm{g} / \mathrm{ml})$ to plasma, acid extraction was performed in an ice-cold water bath by addition of $1 \mathrm{M} \mathrm{HCl}$ to $\mathrm{pH} 4$. The extracts were centrifuged at $8000 \mathrm{~g}$ for 20 minutes at $4^{\circ} \mathrm{C}$, and the acidic supernatants were loaded onto Sep-Pak Vac $\mathrm{C}_{18}$ cartridges $(500 \mathrm{mg}$, Waters Associates) equilibrated in acidified water (0.05\% TFA). After washing with acidified water, two stepwise elutions were performed with $15 \%$ and $40 \%$ acetonitrile in acidified water. The $40 \%$ acetonitrile-eluted fractions were lyophilized (Speed-Vac, Savant), reconstituted in MilliQ water (Millipore ${ }^{\mathrm{TM}}$ ) and protein concentration was determined by Micro BCA Protein Assay Reagent Kit (Pierce ${ }^{\mathrm{TM}}$ ). $20 \mu \mathrm{g}$ of total proteins were subjected to reversed-phase HPLC on a narrow-bore $\mathrm{C}_{18}$ reversed-phase column (Delta Pak HPI $\mathrm{C}_{18}, 2 \times 150$ $\mathrm{mm}$, Waters Associates) equilibrated in acidified water. Separation was performed with a linear gradient of $2 \%-60 \%$ acetonitrile in acidified water, over 90 minutes, at a flow rate of $0.25 \mathrm{ml} /$ minute. Absorbance was monitored at $225 \mathrm{~nm}$. The fractions in which penaeidins were expected, as well as control fractions, were further subjected to peptide immunodetection (see above).

\section{Chitin binding activity of the penaeidins}

$20 \mu \mathrm{g}$ of recombinant Pen-3a (Destoumieux et al., 1997) or synthetic $\mathrm{NH}_{2}$-terminal Pen-3a (see above) were used to investigate penaeidin chitin-binding properties using a protocol derived from Kawabata et al. (1996). Briefly, the lyophilized peptides were reconstituted in a solution of $50 \mathrm{mM}$ Tris, $0.1 \mathrm{M} \mathrm{NaCl}$ at pH $8(800 \mu \mathrm{l})$, and incubated for 10 minutes at room temperature with $40 \mathrm{mg}$ of chitin (Sigma, Aldricht). Samples were centrifuged (1000 g, 5 minutes) and supernatants recovered. The precipitated chitin pellets were successively washed with a solution of $50 \mathrm{mM}$ Tris at $\mathrm{pH} 8$ containing $0.1 \mathrm{M} \mathrm{NaCl}$, then $1 \mathrm{M} \mathrm{NaCl}$, and finally incubated in $10 \%$ acetic acid. At every step, incubations were carried out for 10 minutes at room temperature under gentle stirring, and supernatants were recovered by centrifugation. The collected samples were acidified to $\mathrm{pH} 4$ by addition of $0.5 \%$ TFA, and subjected to HPLC on a SuperPac Sephasil $\mathrm{C}_{8}$ column $\left(250 \times 4 \mathrm{~mm}, 5 \mu \mathrm{m}\right.$, Pharmacia $\left.{ }^{\mathrm{TM}}\right)$. Elution was performed with a linear biphasic gradient of $2 \%-18 \%$ acetonitrile in acidified water over 10 minutes and $18 \%-38 \%$ over 60 minutes, at a flow rate of $0.8 \mathrm{ml} /$ minute. For experiments using synthetic Pen-3a $\mathrm{NH}_{2}-$ terminal domain as a control, elution was performed by a linear gradient of $2 \%-80 \%$ acetonitrile over 120 minutes. Detection was monitored by absorbance at $225 \mathrm{~nm}$, and chromatograms obtained for the different samples were compared.

\section{Anti-penaeidin antibodies}

A 20-residue synthetic peptide corresponding to Pen-3a $\mathrm{NH}_{2}$-terminal domain (pEVYKGGYTRPIPRPPPFVRP) was synthesized using the 
Fluoren-9-ylmethoxycarbonyl (F-moc) procedure (gift from JeanPaul Briand, Strasbourg, France). The synthesis products were reconstituted in acidified water and subjected to reversed-phase chromatography on a preparative Aquapore ODS $\mathrm{C}_{8}$ column $(250 \times 10$ $\mathrm{mm}, 20 \mu \mathrm{m}$, Brownlee ${ }^{\mathrm{TM}}$ ) equilibrated in acidified water. Elution was performed by a linear gradient of $2 \%-80 \%$ acetonitrile in acidified water over 120 minutes, at a flow rate of $2.5 \mathrm{ml} / \mathrm{minute}$. The fraction containing the 20-residue peptide was lyophilized and reconstituted in MilliQ water (Millipore ${ }^{\mathrm{TM}}$ ). After mass spectrometry control, the synthetic peptide $(1 \mathrm{mg})$ was coupled to bovine serum albumin (BSA; Boehringer Mannheim) in a molar ratio peptide:BSA of 1:25 (2 hours, room temperature) after activation by 1-ethyl-3-(3dimethylaminopropyl) carbodiimide (EDAC, Pierce).

A rabbit (male, $2 \mathrm{~kg}$ ) was immunized by a first intradermal injection followed by 4 subcutaneous injections of peptide ( $200 \mu \mathrm{g}$ each) in PBS-diluted coupling reaction mixture. Immunoglobulin $\mathrm{G}$ ( $\mathrm{IgG}$ ) were purified from immune sera on a Hitrap protein $G$ sepharose column (Pharmacia).

\section{Immunofluorescence localization of the penaeidins}

After collection (see below), haemocytes were fixed (10 minutes, room temperature) in MAS solution containing $4 \%$ paraformaldehyde, and cytocentrifuged on slides (5 minutes, $200 \mathrm{~g}$ ) using a Cyto-tek centrifuge (Miles scientific). Cells were further permeabilized by immersion (10 minutes) in $20 \mathrm{mM}$ Tris buffer, $\mathrm{pH}$ 7, containing $0.2 \%$ gelatine, $0.5 \%$ Triton $\mathrm{X}-100$ and $50 \mathrm{mM} \mathrm{NH} 4 \mathrm{Cl}$. Saturation was performed by a 1 hour incubation in $5 \%$ gelatine hydrolysate (Bellon, France) and 1\% normal goat serum (Sigma Immunochemicals) diluted in immunofluorescence buffer (IF, Diagnostic Pasteur, France). Slides were incubated successively for 1 hour at room temperature with anti-penaeidin IgG $(10 \mu \mathrm{g} / \mathrm{ml}$ in IF buffer supplemented with 5\% gelatine hydrolysate), and for 1 hour at room temperature, in the dark, with FITC-conjugated goat anti-rabbit IgG (BioSys, France) diluted at 1:500 (v:v) in IF buffer containing $0.005 \%$ (w:v) Evan's blue (Sigma Diagnostics). Finally, the slides were washed and mounted in glycerine buffer (Diagnostic Pasteur, France) for observation by epifluorescence microscopy.

\section{Immunocytochemical localization of the penaeidins}

Whole juvenile animals or dissected tissues were fixed by incubation (24 hours at room temperature) in a solution containing $22 \%$ formalin, $31.5 \%$ ethanol and $11.5 \%$ acetic acid. After dehydration, tissues were embedded in paraffin, 4-6 $\mu \mathrm{m}$ sections cut, mounted on poly-L-lysine slides (O. Keidler GmbH \& Co., Freiburg) and stored at $4^{\circ} \mathrm{C}$ in a dry atmosphere. After rehydration, the sections were incubated at room temperature in a solution of $100 \mathrm{mM}$ Tris, $\mathrm{pH} 7.5,150 \mathrm{mM} \mathrm{NaCl}$, $\mathrm{pH} 7.5$ (20 minutes), and then for 1 hour in the same solution supplemented with $0.5 \%$ (w:v) blocking reagent (Boehringer Mannheim) and 3\% (v:v) normal goat serum (Sigma Immunochemicals). Overnight incubation at $4^{\circ} \mathrm{C}$ was further performed in $3 \mu \mathrm{g} / \mathrm{ml}$ anti-penaeidin IgG diluted in the same buffer. Alkaline phosphatase-labeled goat anti-rabbit IgG (BioSys, France) was diluted at 1:800 (v:v) in identical buffer and slides were incubated for 1 hour at room temperature, followed by a 1 hour incubation in the dark in a solution of $100 \mathrm{mM}$ Tris- $\mathrm{HCl}, 100 \mathrm{mM} \mathrm{NaCl}, 50 \mathrm{mM}$ $\mathrm{MgCl}_{2}$, pH 9.5, containing $0.19 \mathrm{mg} / \mathrm{ml}$ 5-Bromo-4-chloro-3-indolyl Phosphate (BCIP, Sigma), $0.4 \mathrm{mg} / \mathrm{ml}$ Nitro Blue Tetrazolium (NBT, Sigma) and $0.24 \mathrm{mg} / \mathrm{ml}$ levamisole (Sigma). The reaction was stopped by a 15 minute incubation in $1 \mathrm{mM}$ Tris- $\mathrm{HCl}, 0.1 \mathrm{mM}$ EDTA, $\mathrm{pH} 8$. Sections were finally mounted in DPX (BDH) and observed by light microscopy.

\section{Subcellular localization of the penaeidins}

For transmission electron microscopy, cell pellets or tissues were successively fixed (1 hour at $4^{\circ} \mathrm{C}$ ) in $2 \%$ (v:v) glutaraldehyde in PBS and in $1 \%$ (w:v) $\mathrm{OsO}_{4}$ in $\mathrm{PBS}$, and subsequently washed in $\mathrm{PBS}, \mathrm{pH}$ $7.2,10 \%$ sucrose (w:v). Cells were then dehydrated in alcohol and propylene oxide, and embedded in Araldite CY 212 resin (TAAB). Thin sections were cut and routinely contrasted with uranyl acetate and lead citrate according to Reynolds (1963).

For immunogold labelling, pelleted cells were fixed $\left(1\right.$ hour at $\left.4{ }^{\circ} \mathrm{C}\right)$ in $4 \%$ (w:v) paraformaldehyde, $1 \%$ glutaraldehyde, $10 \%$ sucrose (w:v) diluted in PBS, $\mathrm{pH} 7.2$, dehydrated in alcohol and finally embedded in LR White (LRW) resin (TAAB). Thin sections were collected on gold grids and incubated overnight at $4^{\circ} \mathrm{C}$ with $5 \mu \mathrm{g} / \mathrm{ml}$ anti-penaeidin IgG diluted in PBS supplemented with $1 \%$ blocking reagent (Boehringer, Mannheim). The grids were washed 3 times in PBS and incubated with anti-rabbit IgG conjugated to $10 \mathrm{~nm}$ gold particles (diluted 1:25 in same buffer) (Sigma). Finally, sections were contrasted with uranyl acetate in 50\% (v:v) ethanol and examined in a Jeol 120 electron microscope.

Controls were incubations of rabbit pre-immune serum diluted at 1:1000 (v:v) in identical conditions to those used for anti-penaeidin antibodies. Such controls were performed on centrifuged haemocytes, paraffin and ultrathin sections.

\section{Detection of the penaeidins by enzyme-linked immunoassay (ELISA)}

HPLC fractions were obtained from plasma extracts and those where penaeidins were expected, were eluted with $33 \%$ acetonitrile and subjected to ELISA for penaeidin detection. In these assays, synthetic Pen-3a $\mathrm{NH}_{2}$-terminal domain was used as positive control of reactivity while fractions eluted with $27.7 \%$ acetonitrile were used as negative control. All washing steps $(3 \times 3$ minutes $)$ were performed in PBS, $\mathrm{pH}$ 7.4 , supplemented with $0.1 \%$ Tween-20 (PBS-T). The antibodies were diluted in the same buffer containing 5\% gelatine hydrolysate.

Fractions of equal volumes were lyophilized and resuspended in $320 \mu \mathrm{l}$ of $0.05 \mathrm{M}$ carbonate buffer, $\mathrm{pH}$ 9.6. Microtiter plates (Falcon 3912) were coated overnight at $4^{\circ} \mathrm{C}$ with $50 \mu \mathrm{l}$ of the peptide fractions. After washing, the microtiter plates were incubated with blocking buffer (PBS-T containing 20\% gelatine hydrolysate) for 1 hour at $37^{\circ} \mathrm{C}$, washed and incubated with anti-penaeidin $\operatorname{IgG}(4 \mu \mathrm{g} / \mathrm{ml})$ for 1 hour $\left(37^{\circ} \mathrm{C}\right)$ and, after washing, goat anti-rabbit IgG conjugated to alkaline phosphatase (Biosys, 1:4000) was added for 1 hour $\left(37^{\circ} \mathrm{C}\right)$. Finally, the microplate wells were washed and assayed with $1 \mathrm{mg} / \mathrm{ml}$ p-Nitrophenyl Phosphate in $0.2 \mathrm{M}$ Tris- $\mathrm{HCl}, \mathrm{pH} 9.8$, for 30 minutes at $37^{\circ} \mathrm{C}$. The resulting substrate absorbance was measured at $405 \mathrm{~nm}$ using a Multiscan microplate colorimeter (Labsystem).

\section{RESULTS}

\section{Haemocytes are the main site of penaeidin synthesis}

Penaeidin expression was first studied in the blood cells of unchallenged animals (i.e. not infected experimentally with microbes). Northern blot analysis was performed on total RNA $(2 \mu \mathrm{g})$ extracted from haemocytes of 10 animals. Penaeidin probe hybridized to an abundant mRNA of approximately 750 nucleotides for every individual shrimp (Fig. 1). However, the relative amount of penaeidin mRNA detected was rather different among the 10 individual shrimps. By comparing the hybridization signals obtained with the penaeidin and ribosomal ${ }^{32} \mathrm{P}$-labeled probes (STORM ${ }^{\mathrm{TM}}$ quantification), a fivefold difference in relative amounts of penaeidin mRNA was seen between the animals displaying the higher (animal no. 10) and the smaller (animal no. 5) levels of penaeidin expression.

As hybridization intensities were very strong, we assumed that the penaeidins were abundantly expressed in haemocytes. Northern blot analyses were further performed on various shrimp tissues. $10 \mu \mathrm{g}$ total RNA were isolated from haemocytes, eyes, heart, intestine, gills, subcuticular epithelium, brain, testis, 


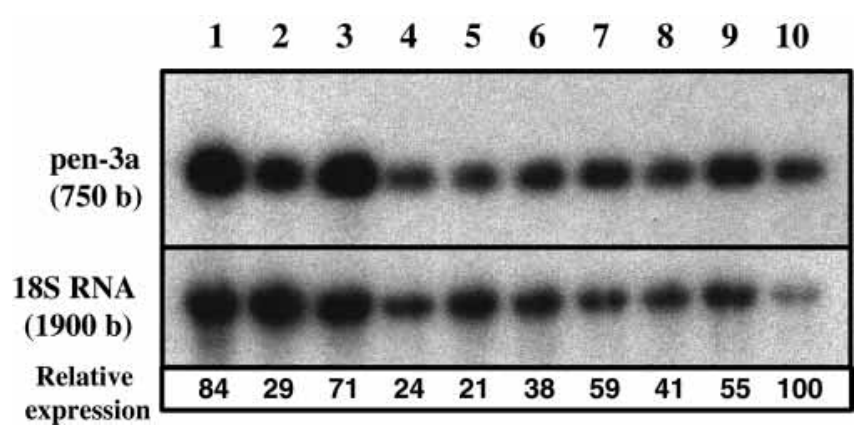

Fig. 1. Northern blot hybridization of penaeidin mRNA in shrimp haemocytes. Total RNA ( $2 \mu \mathrm{g})$ from 10 individual shrimp haemocytes (lanes 1-10) was fractionated by denaturing electrophoresis in a 1\% agarose-formaldehyde gel with Mops buffer, blotted to a Nylon membrane and hybridized successively with random-primed ${ }^{32} \mathrm{P}$-labeled probes specific for pen-3a and $18 \mathrm{~S}$ rRNAs, respectively. The signals on the northern blot were quantified by STORM ${ }^{\mathrm{TM}}$ system. The signal ratio of penaeidin :18S rRNA was obtained for each animal and the highest level of penaeidin expression (animal no.10) was normalized to 100 . The results are given as \% expression relative to this level.

epigastric haematopoietic nodule (lymphoid organ) and hepatopancreas of a single shrimp. Comparison of penaeidin hybridization signals with those obtained using the ribosomal probe demonstrated that haemocytes have a much higher penaeidin mRNA content than detected in other tissues (Fig. 2). However, penaeidin mRNAs were detected in most of the tissues analyzed, and significant mRNA concentrations were observed in heart, gills and epigastric haematopoietic nodules, which are rich in haemocytes, and also in testis. In contrast, no hybridization signal was obtained in the brain (Fig. 2).

\section{Penaeidins are stored in granular haemocytes}

Polyclonal antibodies against penaeidins were raised in rabbits immunized with a synthetic peptide corresponding to Pen-3a $\mathrm{NH}_{2}$-terminal region, i.e. penaeidin proline-rich domain. Using purified anti-penaeidin $\operatorname{IgG}$, the peptide localization within haemocytes was investigated. Immunofluorescence assays showed that different parts of the cytocentrifuged haemocyte population reacted to the specific anti-penaeidin antibody with various staining intensities. A very strong labelling was observed on granule-containing haemocytes, which were easily visualised by Evan's blue counterstaining (Fig. 3). Negative cells were smaller and had no noticeable intracytoplasmic granules (Fig. 3), which suggests that they were hyaline cells.

In an attempt to determine precisely the haemocyte type containing the peptide and its subcellular localization, fixed haemocytes were stained with anti-penaeidin IgG conjugated to $10 \mathrm{~nm}$ gold particles. Electron microscopy confirmed that penaeidins were present in granulocytes. Numerous gold particles were found in the cytoplasmic granules of haemocytes identified, in classical electron microscopy preparations, as large granule haemocytes (Fig. 4a-c). Their numerous granules were large, homogeneous and electron dense. Gold particles were also observed to a lesser extent in some granules of cells identified as small granule haemocytes (Fig. 4d,e). No labelling was found in hyaline cells, which lack such cytoplasmic structures (Fig. 4a,b,d).

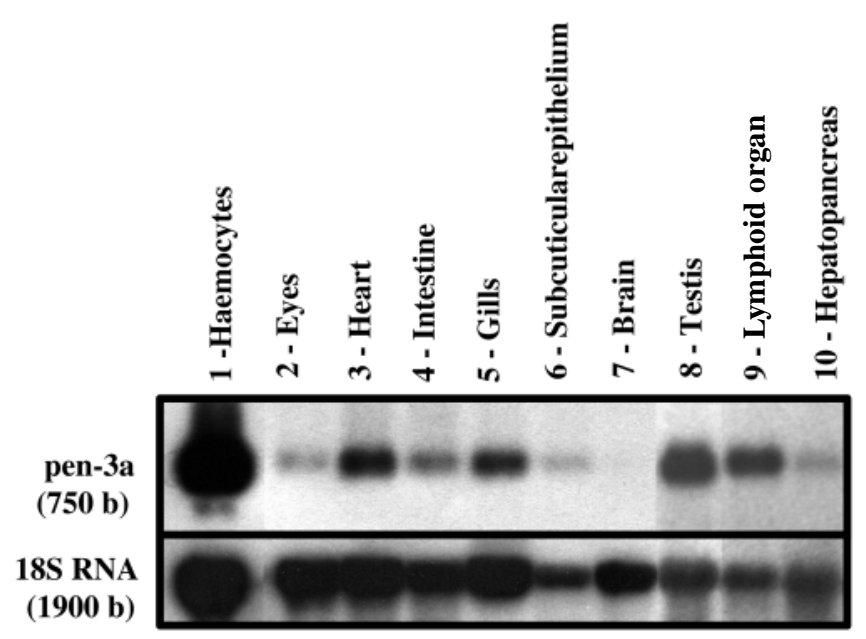

Fig. 2. Northern blot analysis of total RNAs from various shrimp tissues. $10 \mu \mathrm{g}$ of total RNAs from various tissues of a single shrimp were separated by $1 \%$ agarose-formaldehyde gel electrophoresis, blotted to a Nylon membrane and hybridized successively with random-primed ${ }^{32} \mathrm{P}$-labeled pen-3a cDNA then with ${ }^{32} \mathrm{P}$-labeled probe specific for $18 \mathrm{~S}$ rRNAs. Lanes 1, haemocytes; 2, eyes; 3 , heart; 4, intestine; 5 , gills; 6 , subcuticular epithelium; 7, brain; 8 , testis; 9 , epigastric haematopoietic nodule (or lymphoid organ); 10, hepatopancreas.

\section{Penaeidin transcription in haemocytes is not induced by microbial stimulation}

To determine the influence of microbial stimulation on penaeidin transcription in haemocytes, shrimps were experimentally challenged by injection of heat-killed micro-organisms (see Materials and Methods). In two independent experiments, haemolymph was collected at 0, 3, 6, 12 and 24 hours postinjection, and total RNA was extracted from circulating haemocytes. Eight animals were punctured at every time and individual shrimp haemocytes were treated separately. $2 \mu \mathrm{g}$ total RNA were analyzed by northern blot for every shrimp. The STORM $^{\mathrm{TM}}$ quantified penaeidin and ribosomal hybridization signals were compared for every animal, and the individual data were grouped together at each time post-injection. Data analysis
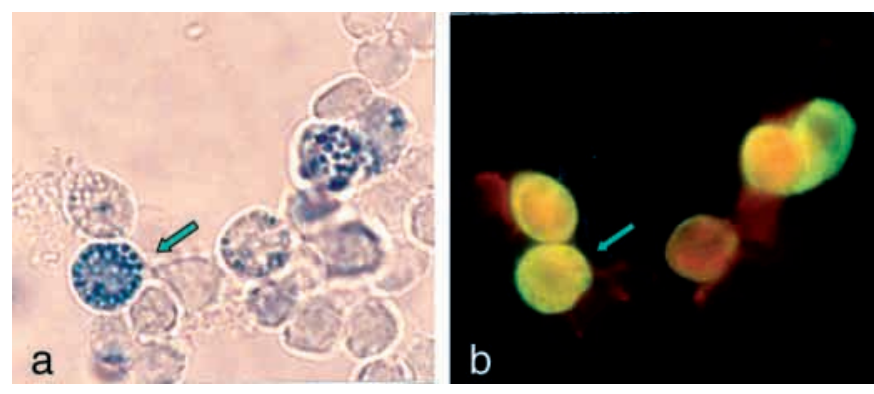

Fig. 3. Immunofluorescence pattern of penaeidin-specific antibody on circulating Penaeus vannamei haemocytes. The haemocytes were cytocentrifuged on slides, permeabilized and stained with antipenaeidin IgG followed by FITC-conjugated anti-rabbit IgG (b); immunoreactivity was found in granular haemocyte populations (arrow) as shown by Evans' Blue counterstaining of the same view observed by light microscopy (a). 

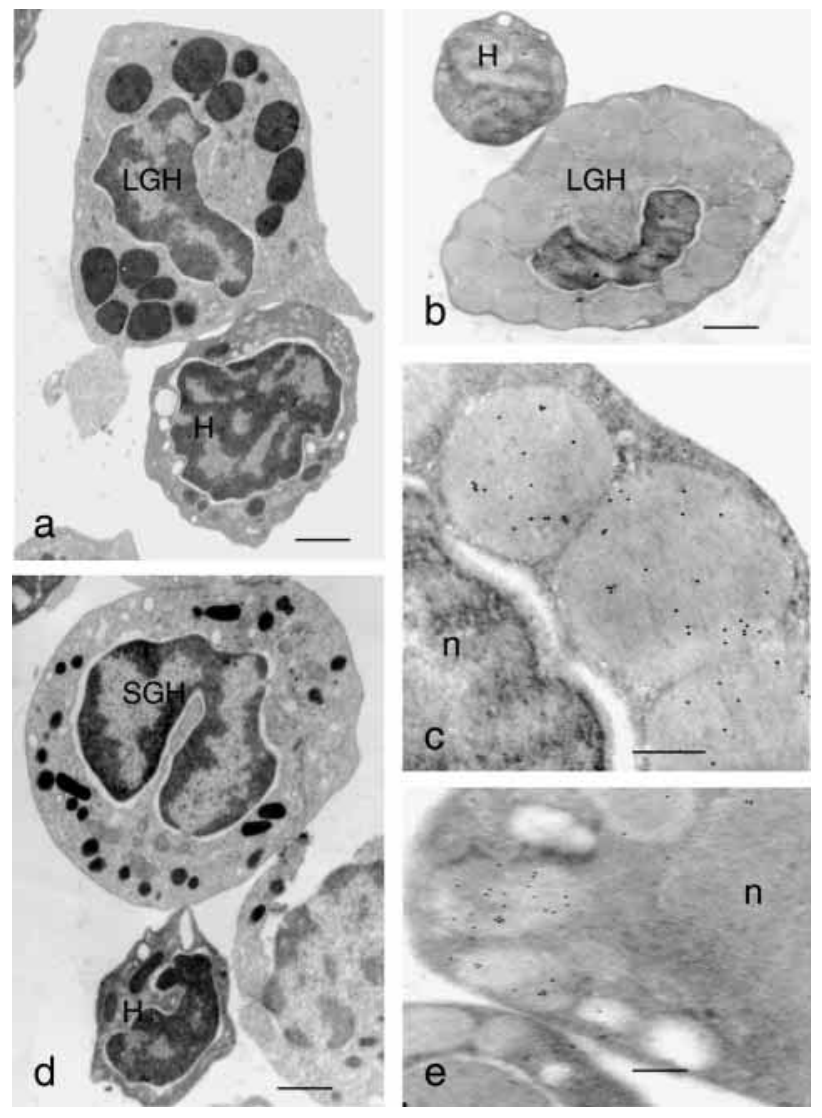

Fig. 4. Ultrastructural localization of penaeidin in shrimp haemocytes. Haemocytes were fixed and embedded, either for ultrastructural examination $(\mathrm{a}, \mathrm{d})$ or for penaeidin immunostaining (b,c,e) using $10 \mathrm{~nm}$ gold particle-conjugated secondary antibody. (a) Section showing large-granule haemocyte (LGH) with numerous, homogeneous, electron-dense granules and a hyaline cell $(\mathrm{H})$ characterized by a high nucleus:cytoplasm ratio. (b) LRW-embedded and immunostained large-granule haemocyte (LGH) and unstained hyaline cell $(\mathrm{H})$. (c) Detail of penaeidin immunostained large-granule haemocyte: gold particles are seen exclusively in cytoplasmic granules. (d) Section showing small-granule haemocytes (SGH) containing small and heterogeneous granules and a hyaline cell $(\mathrm{H})$. (e) Gold particles are observed to a lesser extent in some granules of the small-granule haemocyte. n, nucleus. Bars, $1 \mu \mathrm{m}(\mathrm{a}, \mathrm{b}, \mathrm{d}) ; 500 \mathrm{~nm}$ (c,e).

revealed a four- to fivefold decrease in penaeidin mRNA levels at 3 hours post-injection (Fig. 5). Return to control levels was observed after 12 hours and a slight increase was noticed at 24 hours, but its significance remains to be established. These results were obtained for two experiments independently performed, and even though they do not give precise information in terms of gene regulation, they clearly indicate that penaeidin synthesis in haemocytes is not enhanced by microbial injection.

\section{Penaeidin plasmatic concentration is modulated by microbial stimulation}

In order to verify whether penaeidins are released into the plasma after microbial challenge, we analyzed the plasma contents from 10 individual shrimps collected at different times $(0,1,3,6,24,48$ and 72 hours) following microbial stimulation. Plasma extracts were made by acidification and

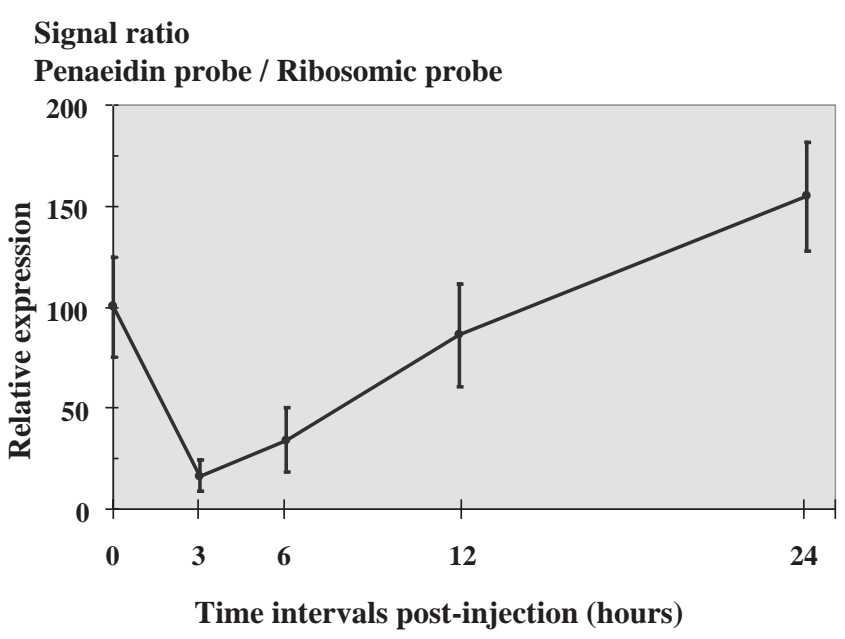

Fig. 5. Time-course analysis of penaeidin expression in haemocytes after microbial challenge. Northern blots of total RNA extracted from shrimp haemocytes at different time intervals after challenge were individually analyzed for 8 animals at each time. For every animal, the signals obtained with penaeidin ${ }^{32} \mathrm{P}$-labeled probe were quantified by the STORM ${ }^{\mathrm{TM}}$ system and compared to those obtained with the $18 \mathrm{~S}$ rRNA specific probe. Mean values at each time were used to determine the penaeidin:18S rRNA signal ratio. Results shown are the mean of two independent experiments. The expression level in unchallenged shrimp was normalized to 100 and results are given as \% expression relative to this level.

solid-phase extraction. The $40 \%$ Sep-Pak fractions, corresponding to $20 \mu \mathrm{g}$ of total proteins in which penaeidins are known to be eluted (as previously established in Destoumieux et al., 1997), were analyzed at each time by reversed-phase HPLC and the peptide was immunodetected by ELISA with the specific antibodies. A fraction eluted with $27.7 \%$ acetonitrile was used as a control. From the chromatograms (Fig. 6A) and ELISA data (Fig. 6B), the penaeidin relative concentration was found to increase by the first 3 hours post-stimulation and reach a maximum at 6 hours. After 24 hours, the plasma content in penaeidins appeared to be similar to that observed in unchallenged animals (time 0), as indicated by ELISA detection.

\section{Immunolocalization of penaeidins in shrimp gills and changes in response to microbial challenge}

The effect of microbial challenge on penaeidin localization in shrimp tissues was investigated in the gills, which are known to be intensely vascularized. Paraffin sections of unchallenged shrimp gills were examined and a positive penaeidin immunoreactivity was seen exclusively in cells apically located in filament blood vessels (Fig. 7c). These cells were identified by electron microscopy examination as granulocytes (Fig. 7a,b). In microbial-challenged shrimps, obvious changes in the penaeidin immunoreactivity pattern were noticed. At 24 hours post-injection, the gills appeared to be specifically labeled at the level of cuticle walls (Fig. 7d) and some immunoreactive spots were also seen in a strikingly central position in the filaments; no labelling was observed in gill sections incubated with rabbit preimmune serum used at a 1:1000 dilution, confirming the specificity of penaeidin immunostaining (Fig. $7 \mathrm{e})$. Finally, in the shrimps analyzed at 72 hours post-injection, 
Fig. 6. Penaeidin levels in shrimp plasma after microbial challenge. Plasma from 10 animals was collected and pooled at different time intervals after microbial challenge, acidified and fractionated onto Sep-Pak $\mathrm{C}_{18}$ cartridges. Equal quantities of proteins $(20 \mu \mathrm{g})$ were subjected to reverse-phase HPLC. (A) Chromatographic profile at $\mathrm{t} 0, \mathrm{t} 3, \mathrm{t} 6, \mathrm{t} 24, \mathrm{t} 48$ and $\mathrm{t} 72$ hours after injection; fractions corresponding to eluted penaeidins are indicated by an arrow and a fraction eluted at $27.7 \%$ acetonitrile and used as control is identified by an asterisk (enlarged and shown for each time interval in the inset). (B) The fractions were analyzed by ELISA for anti-penaeidin reactivity; absorbance at $405 \mathrm{~nm}$ is given for control fractions (grey bars) and penaeidin-containing fractions (hatched bars) at each time interval.

cuticle staining was no longer observed, but the gills contained amorphous, orange-coloured bodies that appeared to be included in nodular formations (Fig. 7f). Similar structures were also seen to a lesser extent in the gills at 24 hours post-challenge. Such observations invite further investigations on gill filaments, in particular through ultrastructural analyses, to understand the extensive modifications that occur in this tissue in response to microbial stimulation.

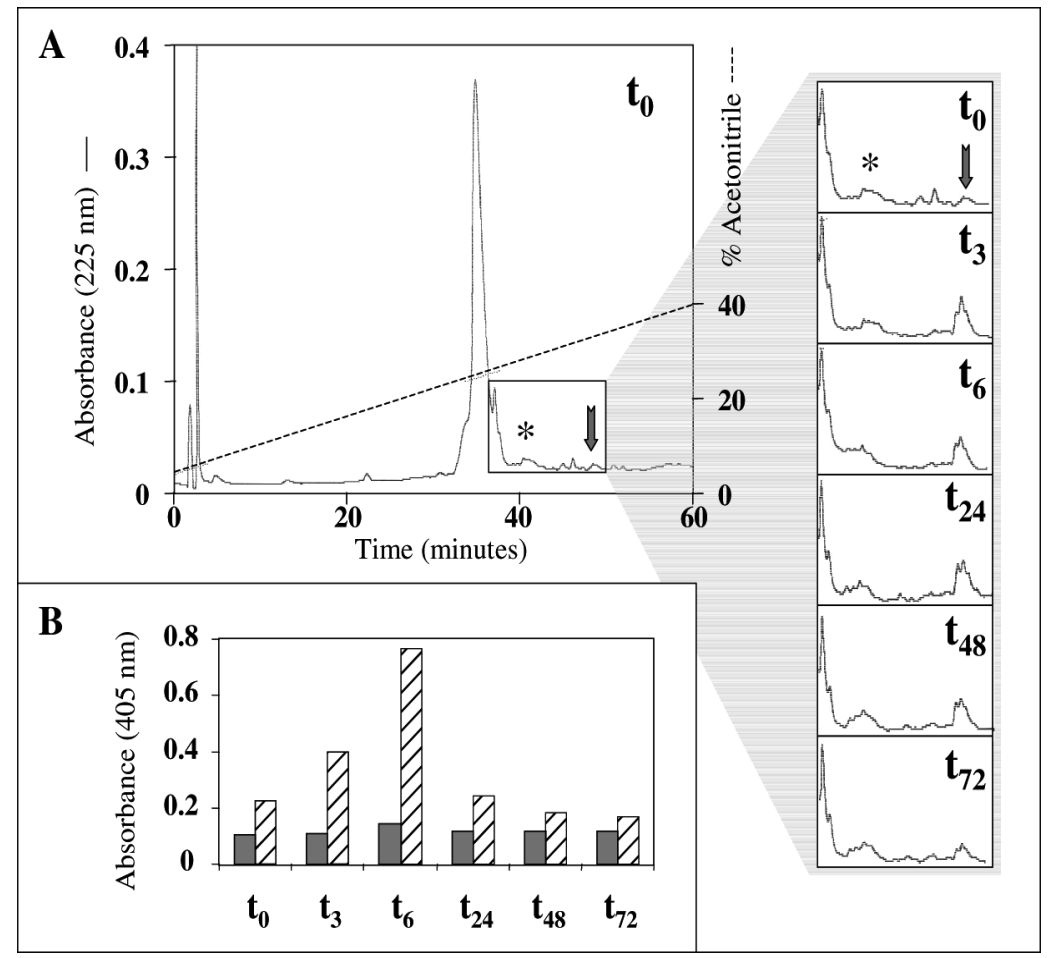

\section{Penaeidins display chitin-binding properties}

The penaeidin immunolocalization observed on gill cuticle after microbial stimulation, together with the identification in the penaeidin $\mathrm{COOH}$-terminal sequence of a partially conserved chitin-binding motif (Bachère et al., 1999), led us to determine whether penaeidins have chitin-binding properties. We used a protocol previously established for the horseshoe crab tachycitin (Kawabata et al., 1996). Recombinant penaeidins (Destoumieux et al., 1999) were incubated with chitin and the supernatants analyzed by HPLC for the presence of penaeidins at the successive steps of chitin precipitation and washes with increasing concentrations of $\mathrm{NaCl}$. Penaeidin was seen to bind tightly to chitin. Indeed, saline buffers (up to $1 \mathrm{M}$ $\mathrm{NaCl}$ ) could not disrupt the penaeidin-chitin interaction and penaeidin could only be recovered in the supernatant after elution with $10 \%$ acetic acid (Fig. 8A). In control experiments with the Pen-3a $\mathrm{NH}_{2}$-terminal domain, which does not present homologies with chitin-binding proteins, we observed that most of the material did not bind to chitin, the main part of it being recovered in the unbound supernatant and in the first wash fractions $(0.1 \mathrm{M} \mathrm{NaCl})$ (Fig. 8B). This demonstrates that

Fig. 7. Immunolocalization of penaeidin in shrimp gills. (a) semi-thin section of secondary gill filaments where haemocytes are observed in vessels (arrow). (b) Electron micrograph of a granular haemocyte in gill blood vessel. (c) Haemocyte (arrow) exhibiting strong immunoreactivity to penaeidin in gill filaments of an unchallenged shrimp. (d) Immunoreactivity pattern of penaeidin in gills of shrimp at 24 hours post-stimulation; note the cuticular labelling (arrow). (e) Absence of labelling in gills of shrimp at 24 hours poststimulation incubated with non-immune rabbit serum. (f) Penaeidin immunoreactivity assay on gills of shrimp at 72 hours poststimulation; no labelling is observed, but numerous amorphous nodular inclusions are scatterred through gill filaments (inset shows detail of a nodular inclusion). Bars, $10 \mu \mathrm{m}$ (a,c-f); $2 \mu \mathrm{m}$ (b). 
Fig. 8. Chitin-binding activity of penaeidins analyzed by reversed-phase HPLC. (A) Purified penaeidins (control) were incubated with chitin. After recovery of the unbound fraction, stepwise elutions were performed with increasing $\mathrm{NaCl}$ concentrations $(0.1 \mathrm{M} \mathrm{NaCl} ; 1 \mathrm{M} \mathrm{NaCl})$, and with $10 \%$ acetic acid. The successive supernatants were loaded onto a $\mathrm{C}_{8}$ reversed-phase column and chromatograms were compared to the control profile. Separation was monitored by a biphasic linear gradient of $2 \%-18 \%$ acetonitrile over 10 minutes and $18 \%$-38\% over 60 minutes at a flow-rate of $0.8 \mathrm{ml} /$ minute. (B) Control was performed in identical conditions using the penaeidin $\mathrm{NH}_{2}$-terminal domain. Separation was monitored by a linear gradient of $2 \%-80 \%$ acetonitrile over 120 minutes at a flow rate of $0.8 \mathrm{ml} /$ minute.

the Pen-3a $\mathrm{NH}_{2}$-terminal domain alone does not display specific binding to chitin, but that the entire molecule is able to attach chitin tightly.

\section{DISCUSSION}

Penaeidins are a family of antimicrobial peptides characterized in the shrimp Penaeus vannamei. They were isolated in a mature form from organelle-rich extracts of shrimp haemocytes and were also found in plasma (Destoumieux et al., 1997). In order to understand the function of these antimicrobial peptides in shrimp defense, we examined the tissue localization of penaeidin mRNA and mature peptide in normal shrimp, i.e. unchallenged animals, as well as the penaeidin expression pattern in response to an experimental microbial challenge. In these experiments, we used Pen-3a specific probes (both antibodies and cDNA probes), as this peptide occurs as the most abundant penaeidin in natural extracts (Destoumieux et al., 1997). These probes, which also detect Pen-1 and Pen-2 (data not shown), do not attempt to discriminate between the different members of the penaeidin family, and were considered to be adequate for a first general study of penaeidin expression in shrimp.

Penaeidin expression in unchallenged animals was first studied in haemocytes from which the peptide cDNA had been cloned (Destoumieux et al., 1997). A high level of penaeidin mRNA was measured in all of the juvenile shrimps analyzed, suggesting that these peptides are constitutively expressed in haemocytes. However, individual variability was seen, which could reflect either different immune stimulation states of animals or a genetic variability in penaeidin gene expression. Furthermore, northern blot analyses performed with RNA extracted from haemocytes and other tissues indicated that haemocytes were the main site of penaeidin synthesis. Weaker hybridization signals were observed in tissues such as heart, gills, testicle and epigastric haematopoietic nodules, probably due to infiltrating haemocytes. The amount of penaeidin transcripts was negligible in the intestine, hepatopancreas, eyes and subcuticular epithelium of unchallenged shrimps, and undetectable in the brain. These findings are consistent with the haemocytic production of antimicrobial peptides shown in horseshoe crabs (Shigenaga et al., 1990), but this remains to

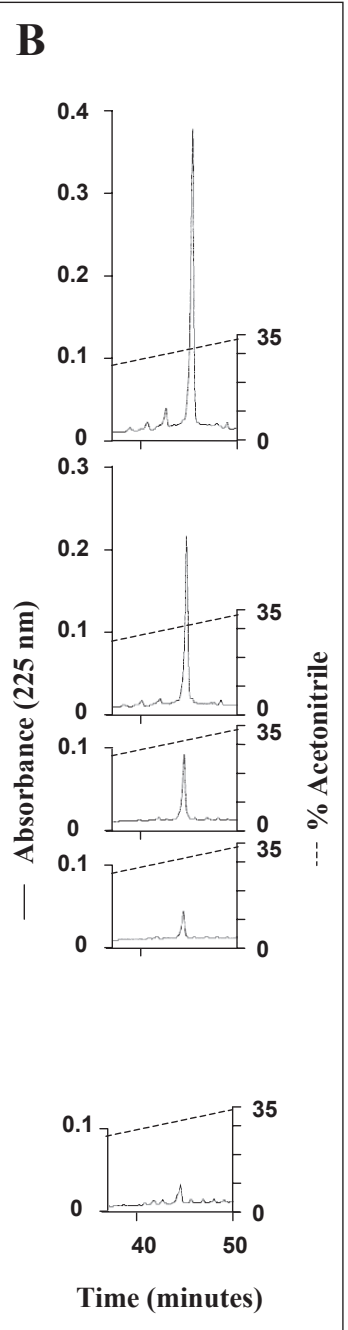

be confirmed by in situ hybridization studies on tissue sections. Penaeidin expression in haemocytes is associated with storage in granular haemocytes, as demonstrated by immunolabelling. Ultrastructural localization of penaeidins showed a granular location, mainly observed in large granule haemocytes, but some labelling was also found to a lesser extent in the small granule haemocytes, also called semi-granulocytes (Martin and Hose, 1992). In contrast, the hyaline cells appeared to be devoid of penaeidins. Whether penaeidin transcription may occur in this cell population or is specific to the granular celltypes remains unknown.

Despite the development of monoclonal antibodies as markers (Rodriguez et al., 1995), cytochemical criteria and functional studies (Hose et al., 1990; Gargioni and Barracco, 1998), discrimination between haemocyte cell-types in crustaceans remains difficult. Therefore, our study on the localization of penaeidin expression provides an additional tool for the identification of the different types of the shrimp blood cells. Our observations are consistent with the existence of two major distinct groups or lineages: (1) the hyaline haemocytes, involved in coagulation processes, and (2) the granulocytes, including small and large granule haemocytes, active in phagocytosis and encapsulation, which contain lysosomal enzymes, prophenoloxidase activity (see Martin and Hose, 
1992) and, according to the present study, antimicrobial peptides.

Localization of penaeidin in granulocytes indicates that they would not be directly secreted into the plasma following synthesis, but rather would be retained in a mature form in cytoplasmic storage granules. Therefore, similar to human neutrophil defensins (for a review, see Selsted and Ouellette, 1995), penaeidins could contribute to the elimination of microorganisms engulfed by granulocytes during phagocytosis. Further studies involving in vitro experimental infections of shrimp haemocytes should address this issue. Among arthropods, similar granular storage was shown in horseshoe crabs (chelicerata) where, upon stimulation by lipopolysaccharidic or $\beta$-glucan compounds, haemocytes degranulate immediately in vitro and release their granular content, including antimicrobial peptides, into the blood (reviewed by Iwanaga and Kawabata, 1998).

While there are no reported data on a possible transcriptional regulation of antimicrobial peptide expression in horseshoe crab haemocytes, in vivo microbial challenge in shrimp showed that penaeidin gene transcription is not stimulated in haemocytes. On the contrary, penaeidin mRNA concentration (relative to $18 \mathrm{~S}$ rRNA concentration) drops in circulating haemocytes in the early hours after challenge, and then returns to initial levels at about 12 hours post-injection. This contrasts with the data on antimicrobial peptide gene regulation in insects, where transcription is induced upon in vivo microbial stimulation (Hoffmann and Reichhart, 1997; Engström, 1998). Such a decrease in penaeidin messenger concentration could be associated with a partial decrease of penaeidin-producing haemocytes from the blood stream. Even though further studies are necessary to determine with accuracy the changes in the ratio of penaeidin-expressing haemocytes in the total population of circulating cells, we observed in this study that total haemocyte counts were strongly affected by microbial challenge (data not shown), as previously mentioned in other crustacean species (Smith and Söderhäll, 1983a; Martin et al., 1993). Such modifications could be due to haemocyte lysis, as proposed by Omori et al. (1989), to cell recruitment towards injured tissues or to nodule formation (Martin et al., 1998), and could consequently induce an apparent decrease in penaeidin mRNA concentration. On the other hand, the microbial challenge could also lead to a decrease in penaeidin gene transcription subsequent to degranulation events and release of the peptides into the blood. Actually, microbial stimulation is known to trigger haemocyte degranulation as one of the most immediate haemocytic reactions in crustaceans (Smith and Söderhäll, 1983b; Johansson and Söderhäll, 1985), and in the freshwater crayfish Pacifastacus leniusculus, degranulation was shown to be associated with a rapid decrease in RNA and protein synthesis in granular cells (Johansson and Söderhäll, 1989).

As described for Limulus (Toh et al., 1991), and to some extent for mammalian antimicrobial peptides, some of the penaeidins stored in blood cells appear to be released into haemolymph upon stimulation. Actually, HPLC analyses of plasma samples of challenged shrimps, followed by the immunodetection of the peptides, showed a relative increase of penaeidins in shrimp plasma at 6 hours post-injection. This also corroborated the results of tissue immunohistological analyses at different times post-stimulation. In the gills in particular, the penaeidin immunoreactive pattern was obviously different after microbial stimulation. At 24 hours post-injection, immunoreactivity was found in the cuticle, when penaeidins were no longer detected in haemocytes located in the efferent blood vessels, as seen for unchallenged animals. This cuticular localization is consistent with the strong affinity for chitin (a major component of shrimp cuticle) displayed by penaeidins that we observed in this study. From our experiments, chitin binding is probably mediated by the penaeidin $\mathrm{COOH}$-terminal domain, i.e. cysteine-rich region, which displays a partial conservation of the chitin-binding motif (Bachère et al., 1999). We can therefore speculate that after haemocytic release into the plasma, penaeidins tightly attach to the shrimp cuticular surfaces where, by their chitinbinding property, the peptides could prevent the shrimp from invasive infections by a systemic protection. Finally, at 72 hours, penaeidin immunoreactivity became undetectable on gill tissue and on infiltrating haemocytes. Histological observations revealed a significant phenomenon of clumping and nodular formation of amorphous material, probably related to haemocyte nodule formation and lysis (Smith and Ratcliffe, 1980; Martin et al., 1998).

Finally, if haemocytes infiltrating into shrimp tissues may spread penaeidins through exocytosis in response to injury or infection, a transcriptional induction of penaeidin expression in tissues must also be considered, as a possible local protection system against invading micro-organisms, and as observed for some of the vertebrate antimicrobial peptides (reviewed in Ganz and Lehrer, 1998).

In conclusion, from this study, penaeidin function may not be limited to antimicrobial activities, but is likely to extend to additional properties. For instance, penaeidin chitin-binding ability could not only be essential for their antifungal activity but could also be involved in chitin assembly or wound healing, as suggested for the horseshoe crab tachycitin (Kawabata et al., 1996). Penaeidins could play a role in the protection of shrimps that are particularly exposed to microbial infection during the moulting cycle. With respect to the penaeidin properties, it will also be advisable to consider their gene expression during development and reproduction events. With an interest in comparative fundamental aspects, this knowledge will be particularly important for further investigations dealing with the establishment of disease control in penaeid shrimp production (Bachère, 1999).

We warmly thank Céline Jouffrey and Julien Garnier for their technical assistance, Guillaume Mitta for critical advice on this work and Dr Esther Lubzens and Jean-Christophe Avarre for supplying shrimp rRNA $18 \mathrm{~S}$ probe. This work is supported by IFREMER (Institut Français de Recherche et d'Exploitation de la Mer), CNRS (Centre National de la Recherche Scientifique) and the University of Montpellier 2.

\section{REFERENCES}

Bachère, E. (1999). Shrimp immunity and disease control. Aquaculture, in press.

Bachère, E., Destoumieux, D. and Bulet, P. (1999). Penaeidins, antimicrobial peptides of shrimp: a comparison with other effectors of innate immunity. Aquaculture, in press.

Destoumieux, D., Bulet, P., Loew, D., van Dorsselaer, A., Rodriguez, J. and Bachère, E. (1997). Penaeidins, a new family of antimicrobial peptides 
isolated from the shrimp Penaeus vannamei (Decapoda). J. Biol. Chem. 272, 28398-28406

Destoumieux, D., Bulet, P., Strub, J.-M., Van Dorsellaer, A. and Bachère, E. (1999). Recombinant expression and range of activity of penaeidins, antimicrobial peptides from penaeid shrimp. Eur. J. Biochem. 266, 335-346.

Engström, Y. (1998). Insect immune gene regulation. In Molecular Mechanisms of Immune Responses in Insects (ed. P. T. Brey and D. Hultmark), pp. 211-244. London: Chapman \& Hall.

Ferrandon, D., Jung, A. C., Criqui, M. C., Lemaitre, B., UttenweilerJoseph, S., Reichhart, J.-M. and Hoffmann, J. A. (1997). A drosomycinGFP reporter transgene reveals a local immune response in Drosophila that is not dependent on the Toll pathway. EMBO J. 17, 1217-1227.

Ganz, T. and Lehrer, R. (1998). Antimicrobial peptides of vertebrates. Curr. Opin. Immunol. 10, 41-44.

Gargioni, R. and Barracco, M. A. (1998). Hemocytes of the Palaemonids Macrobachium rosenbergii and M. acanthurus, and of the Penaeid Penaeus paulensis. J. Morphol. 236, 209-221.

Hoffmann, J. A. and Reichhart, J.-M. (1997). Drosophila immunity. Trends Cell Biol. 7, 309-316.

Hose, J. E., Martin, G. G. and Gerard, A. S. (1990). A decapod classification scheme integrating morphology, cytochemistry, and function. Biol. Bull. 178, 33-45.

Iwanaga, S. and Kawabata, S.-I. (1998). Evolution and phylogeny of defense molecules associated with innate immunity in horseshoe crab. Front. Biosci. 3, D973-D984.

Johansson, M. W. and Söderhäll, K. (1985). Exocytosis of the prophenoloxidase activating system from crayfish haemocytes. J. Comp. Physiol. B 156, 175-181.

Johansson, M. W. and Söderhäll, K. (1989). Cellular immunity in crustaceans and the proPO system. Parasitol. Today 5, 171-176.

Kawabata, S. I., Nagayama, R., Hirata, M., Shigenaga, T., Agarwala, K. L., Saito, T., Cho, J., Nakajima, H., Takagi, T. and Iwanaga, S. (1996). Tachycitin, a small granular component in horseshoe crab hemocytes, is an antimicrobial protein with chitin-binding activity. J. Biochem. (Tokyo) 120, 1253-1260.

Khoo, L., Robinette, D. W. and Noga, E. J. (1999). Callinectin, an antibacterial peptide from blue crab, Callinectes sapidus, hemocytes. Mar. Biotechnol. 1, 44-51.

Lemaitre, B., Nicolas, E., Michaut, L., Reichhart, J.-M. and Hoffmann, J. A. (1996). The dorsoventral regulatory gene cassette spätzle/Toll/cactus controls the potent antifungal response in Drosophila adults. Cell 86, 973-983.

Manetti, A. G. O., Rosetto, M. and Marchini, M. (1998). Antibacterial peptides of the insect reproductive tract. In Molecular Mechanisms of Immune Responses in Insects (ed. P. T. Brey and D. Hultmark), pp. 67-91. London: Chapman \& Hall.
Martin, G. G. and Hose, J. E. (1992). Vascular elements and blood (hemolymph). In Microscopic Anatomy of Invertebrates, vol. 10 (ed. F. W. Harrison and A. G. Hurnes), pp. 117-146. New York, Chichester, Brisbane, Toronto, Singapore: John Wiley \& Sons.

Martin, G. G., Kay, J., Poole, D. and Poole, C. (1998). In vitro nodule formation in the ridgeback prawn, Sycionia ingentis, and the american lobster, Homarus americanus. Invertebr. Biol. 117, 155-168.

Martin, G. G., Poole, D., Poole, C., Hose, J. E., Arias, M., Reynolds, L., McKrell, N. and Whang, A. (1993). Clearance of bacteria injected into the hemolymph of the penaeid shrimp, Sicyonia ingentis. J. Invertebr. Pathol. 62, 308-315.

Omori, S. A., Martin, G. G. and Hose, J. E. (1989). Morphology of hemocyte lysis and clotting in the ridgeback prawn, Sicyonia ingentis. Cell Tissue Res. 255, 117-123.

Reynolds, E. S. (1963). The use of lead citrate at high $\mathrm{pH}$ as an electronopaque stain in electron microscopy. J. Cell Biol. 17, 208-212.

Rodriguez, J., Boulo, V., Mialhe, E. and Bachère, E. (1995). Characterization of shrimp haemocytes and plasma components by monoclonal antibodies. J. Cell Sci. 108, 1043-1050.

Schnapp, D., Kemp, G. D. and Smith, V. J. (1996). Purification and characterization of a proline-rich antibacterial peptide, with sequence similarity to bactenecin-7, from the haemocytes of the shore crab, Carcinus maenas. Eur. J. Biochem. 240, 532-539.

Selsted, M. E. and Ouellette, A. J. (1995). Defensins in granules of phagocytic and non-phagocytic cells. Trends Cell Biol. 5, 114-119.

Shigenaga, T., Muta, T., Toh, Y., Tokunaga, F. and Iwanaga, S. (1990) Antimicrobial tachyplesin peptide precursor. cDNA cloning and cellular localization in the horseshoe crab (Tachypleus tridentatus). J. Biol. Chem. 265, 21350-21354.

Smith, V. J. and Ratcliffe, N. A. (1980). Cellular defense reactions of the shore crab, Carcinus maenas: in vivo hemocytic and histopathological responses to injected bacteria. J. Invert. Pathol. 35, 65-74.

Smith, V. J. and Söderhäll, K. (1983a). Induction of degranulation and lysis of haemocytes in the freshwater crayfish, Astacus astacus by components of the prophenoloxidase activating system in vitro. Cell Tissue Res. 233, 295-303.

Smith, V. J. and Söderhäll, K. (1983b). Beta-1,3 glucan activation of crustacean hemocytes in vitro and in vivo. Biol. Bull. 164, 299-314.

Söderhäll, K., Iwanaga, S. and Vasta, G.R. (1996). New Directions in Invertebrate Immunology (SOS Publications). New Jersey: Fair Haven.

Toh, Y., Mizutani, A., Tokunaga, F., Muta, T. and Iwanaga, S. (1991). Morphology of the granular hemocytes of the Japanese horseshoe crab Tachypleus tridentatus and immunocytochemical localization of clotting factors and antimicrobial substances. Cell Tissue Res. 266, 137 147. 